\section{Commercial Transplant Production Practices and Recent Research in Japan}

\section{Toyoki Kozai and Tadashi Ito}

Additional index words. seedling, plug, grafted transplants, micropropagated transplants

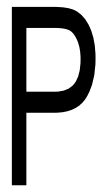

resent Japanese horticulture is characterized by: 1) its small-scale family operations; 2) a high percentage of elderly growers; 3 ) labor-intensive cultivation methods; 4) a shortage of part-time workers, with relatively high wages for farm laborers; and 5) consumer demand for high-quality products.

Due to the high demand for quality transplants at low prices, intensive research and development on commercial transplant production systems are underway in private and public sectors. Present practices and recent research on transplant production systems are reviewed brieflyhere, with some emphasis on grafted and micropropagated transplants. Detailed descriptions are given on plug production, automation of transplant production, and environmental control in micropropagation in Japan. Unless otherwise defined, plug means plug seedling and/or plug transplant.

\section{Plug production}

General background. The commercial plug production system was introduced to Japan in 1985 from the United States. Since then, the production system has been modified to meet Japanese needs. Japanese technology, however, is still, in many respects, several years behind the United States, Italy, and the Netherlands.

Since 1985, commercial transplant production has increased rapidly. About 100 million plugs (22 million lettuce, 8 million broccoli, 6 million cabbage, 4 million tomato, 3 million onion, 20 million bedding plants, 17 million cut flowers, 8 million pot plants) were produced com-

Faculty of Horticulture, Chiba University Matsudo, Chiba 271, Japan. mercially in 1990, compared to 60 million in 1989. Cultural practices. Tray sizes range in width between 290 and $300 \mathrm{~mm}$, in length between 560 and $600 \mathrm{~mm}$, and in depth between 25 and 50 $\mathrm{mm}$. Number of cells per tray range between 50 and 400 , and medium volume per cell ranges between 8 and $30 \mathrm{ml}$. The most common cell size for lettuce plugs, for example, is $20 \times 20 \mathrm{~mm}$ at the top, $10 \times 10 \mathrm{~mm}$ at the bottom, and $40 \mathrm{~mm}$ deep in a tray with 253 cells. Scandinavian and Canadian peatmoss is the main medium ingredient; it is mixed with some perlite, vermiculite, granulate, etc. Typical physical/chemical parameters of the media are $15 \%$ to $35 \%(\mathrm{v} / \mathrm{v})$ for water content, 0.6-1.1 for apparent specific gravity, 5-15S/m for electric conductivity, and 6-7 for $\mathrm{pH}$. Several kinds of fertilizers developed for hydroponic culture generally areapplied with the irrigation water. The main composition of the most commonly used nutrient solution, Enshi-shoho, is $950 \mathrm{~g} \mathrm{~m}^{-3}$ of $\mathrm{Ca}\left(\mathrm{NO}_{3}\right)_{2} 4 \mathrm{H}_{2} \mathrm{O}, 810 \mathrm{~g} \mathrm{~m}^{-3}$ of $\mathrm{KNO}_{3}, 500 \mathrm{~g} \mathrm{~m}^{-3}$ of $\mathrm{MgSO}_{4} \mathrm{H}_{2} \mathrm{O}, 155 \mathrm{~g} \mathrm{~m}^{-3}$ of $\mathrm{NH}_{4} \mathrm{H}_{2} \mathrm{PO}_{4}$, and $20 \mathrm{~g} \mathrm{~m}^{-3}$ of $\mathrm{NaFe}$-EDTA, with some other minor elements. Both overhead and sub-irrigation systems are used, but overhead irrigation systems are dominant due to their simplicity. Carbon dioxide enrichment has been employed only occasionally on a commercial scale. Hardening is started $\approx 1$ week prior to shipping, mainly by lowering the temperature, reducing the amount of irrigation water, and modifying the fertilizer composition (high $\mathrm{K}$ and low N).

Overnight delivery by truck is used for transportation of transplants packed in paper cartons

Table 1. Japanese hectarage of vegetable plants using grafted transplants.

\begin{tabular}{|lccc|}
\hline & \multicolumn{3}{c}{$\begin{array}{c}\text { Hectares } \\
\text { planted }\end{array}$} \\
Crops & $\begin{array}{c}\text { Planted with } \\
\text { grafts } \\
(1000)\end{array}$ & $\begin{array}{c}\text { Total } \\
\text { grafted } \\
(\%)\end{array}$ \\
\hline Wa te r m e I o n & 28 & 27 & 96 \\
Cucumber & 22 & 11 & 50 \\
Muskmelon & 1.2 & 0.5 & 42 \\
Cantaloupe & 7.7 & 5.7 & 74 \\
Tomato & 12 & 1.2 & 10 \\
Eggplant & 15 & 4.3 & 29 \\
\hline
\end{tabular}

zFrom the Japanese Ministry of Agriculture, Forestry and Fisheries (1991).

Table 2. Scion-rootstock combinations widely accepted for producing grafted vegetable transplants (Ito, 1992).

Scion Rootstocks

Citrullus lanatus (Matsum. et Nakai)

Cucumis sativus L.

Cucumis melo L. (var. cantalup.)

Cucumis melo L. (var. reticulatus)

Cucumis melo L. (var. conomon)

Lycopersicon esculentum

Solanum melong $\mathrm{L}$. with side vents. Vegetable plugs are transplanted mostly by hand into holes of plastic-mulched fields. Mulching is used commonly in vegetable production. In the case of mechanical transplanting, if plugs are too large to pass through mechanical transplanter, leaf pruning is carried out. Leaf pruning of lettuce plugs results in enhancement of root growth (Ito, 1992). For short-term storage (a few weeks) of plugs, a cold room (3-6C) with dim light (20-100 lux) from fluorescent lamps is often used commercially, but no published data are available.

Vegetable plugs cost from US\$0.06 to US\$0.10/plug. Because transplant cost generally accounts for $<10 \%$ of the total production cost, growers tend to favor using commercially produced plugs.

Grafted transplants. Grafting is used widely for producing melons and tomato transplants tolerant to low temperature and soil-borne pathogens, such as Fusarium spp. and certain kinds of bacteria.

Table 1 outlines the relative percentage of vegetables established using grafted transplants. Table 2 shows scion-rootstock combinations widely accepted for producing grafted vegetable transplants. The price of grafted transplants ranged from US\$0.50 to US\$2.00 per transplant, depending on cultivar.

At present, most grafted transplantsare produced by growers for their own use. Conventional grafting methods used are: hole method, tongue method, whip method, and wedge method (Ito, 1992). With these methods, only 65 to 80 grafted transplants are produced per person per hour-this must be improved for commercial mass-production of grafted transplants to be feasible.

An improved whip grafting method using a cylindrical supporting collar was developed recently for solanaceous (tomato and eggplants) plants by Agricultural Technology Center, National Federation of Agricultural Cooperation Associate, Kanagawa. The supporting collar drops naturally from the transplant as the stem increases in diameter. With this method, $\approx 150$ grafted transplants are produced per person per hour.

Improved whip grafting is done at the 2.5- 
true-leaf stage of scion and rootstock, rather than the 5-true-leaf stage with the traditional grafting methods. Trays $(300 \times 600 \mathrm{~mm})$ contain 51,73 , or 96 cells, and grafted transplants are transferred to a growth room illuminated by fluorescent lamps. Grafts are cured and acclimatized for 3 days at 25-
28C, $90 \% \mathrm{RH}, \mathrm{CO}_{2}$ concentration of $350-600$ $\mathrm{mol} \cdot \mathrm{mol}^{-1}$, photoperiod of $12 \mathrm{~h} /$ day, photosynthetic photon flux density (PPFD) of 300-500 $\mathrm{mol} \cdot \mathrm{m}^{-2} \cdot \mathrm{s}^{-1}$ air flow speed of $300 \mathrm{~mm} \cdot \mathrm{s}^{-1}$ After acclimatization under the fluorescent lamps for a few days, the transplantsare transferred to the

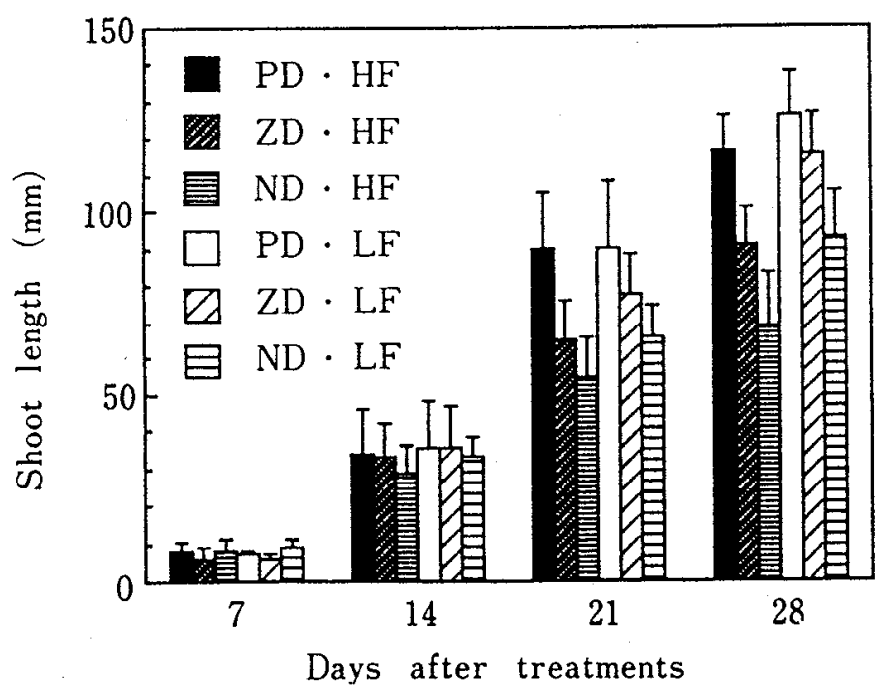

Fig. 1. Shoot length of potato plantlets cultured in vitro $7,14,21$, and 28 days after treatments. DIF is defined as the difference in air temperature $\left({ }^{\circ} \mathrm{C}\right.$ ) between photoperiod and dark period (photoperiod $\mathrm{T}$ - dark period $\mathrm{T}$ ). $\mathrm{PD}, \mathrm{ZD}$, and ND denote, respectively, $+10 \mathrm{DIF}$, zero DIF, and $-10 \mathrm{DIF}$. Daily average of air temperature was $20 \mathrm{C}$ in all the treatments $\mathrm{HF}$ and LF denote, respectively, high PPFD $\left(147 \mu \mathrm{mo} \cdot \cdot \mathrm{m}^{-2} \cdot \mathrm{s}^{-1}\right)$ and low PPFD $\left(74 \mu \mathrm{mol} \cdot \mathrm{m}^{-2} \cdot \mathrm{s}^{-1}\right)$ (Kozai et al., 1992a).

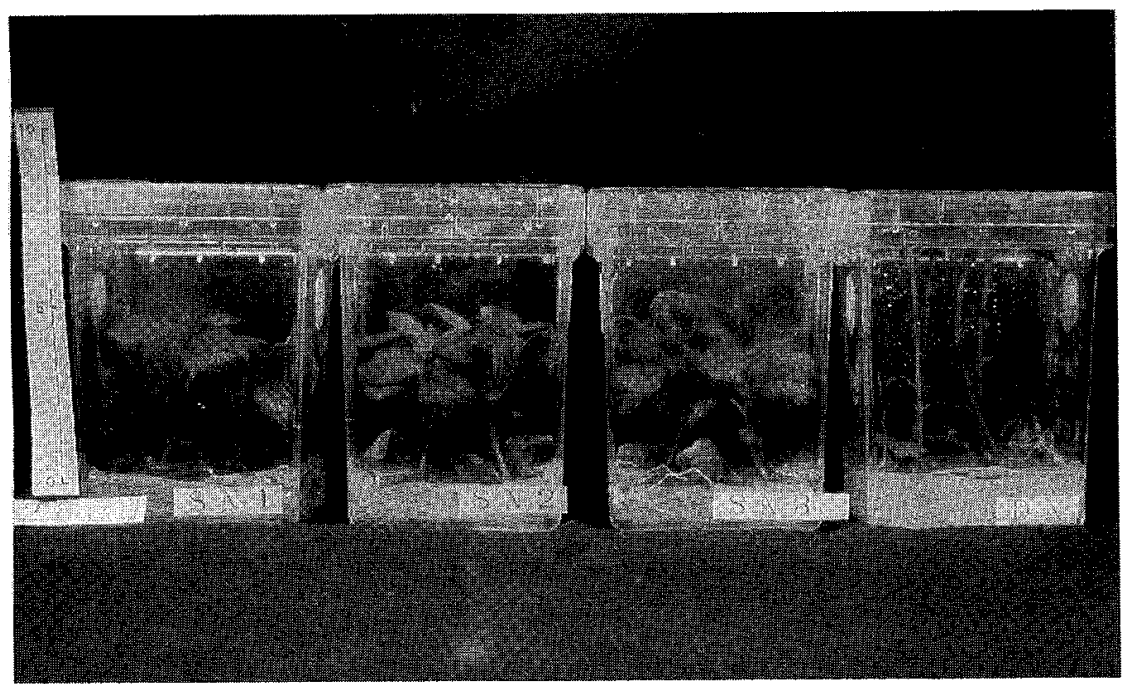

Fig. 2. Potato plantlets cultured in vitro for 28 days in the sideward and downward lighting systems shown in Fig. 2 (Hayashi et al, 1992)

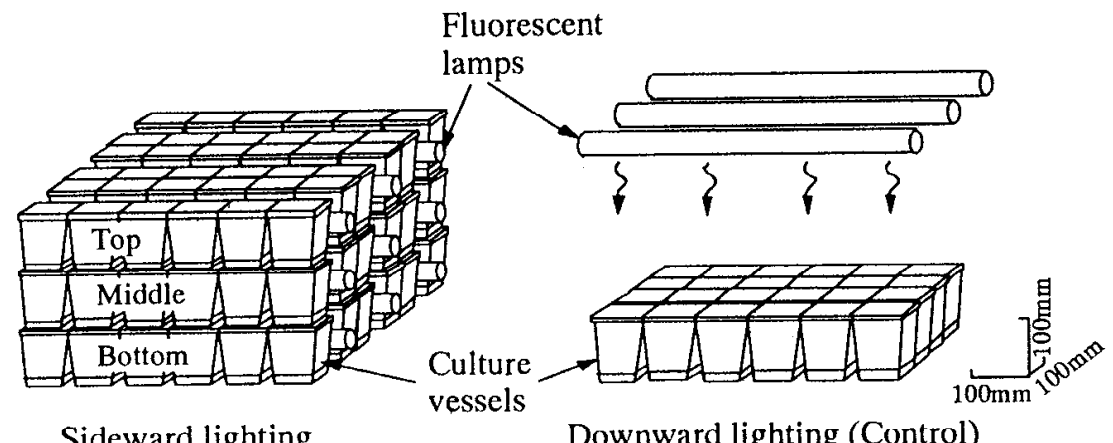

Sideward lighting

Downward lighting (Control)

Fig. 3. A schematic diagram of the sideward and downward (conventional) lighting systems using fluorescent lamps (Hayashi et al., 1992b). greenhouse for further growth. The appearance of grafted transplants in the tray is just like seeded plugs. Transplants produced with this method have been accepted widely by tomato and eggplant growers.

Micropropagated transplants. In 1991, there were $\approx 6000$ ha and 580 ha of strawberries and carnations, respectively. The mother plants are commonly micropropagated. Micropropagated mother plants are propagated vegetatively, and each mother plant produces50 to 100 transplants. The micropropagated transplants are placed in the greenhouse with fine nets for protection from insects.

Micropropagation is used for orchids (Cymbidium), Gypsophila, Limonium, gerbera, Chinese yam (Dioscorea opposita), asparagus, taro, garlic, lily, etc. These micropropagated plants are not propagated vegetatively for further multiplication in the greenhouse, but are transferred and acclimatized to the transplant stage in the greenhouse or open fields directly from tissue-culture vessels. Computer-controlled acclimatization units with shading, fogging, and $\mathrm{CO}_{2}$ enrichment systems have been developed (Kozai et al., 1987), but are used commercially infrequently. Micropropagated transplants cost from US $\$ 0.50$ to US $\$ 2.00$ per transplant. The use of micropropagated transplants has increased recently not only for ornamentals, but also for vegetables and some food crops such as sweetpotatoes.

\section{Research on environmental control and automation}

Height control of transplants. Height control of transplants is still ongoing in Japan. Techniques for height control in micropropagated transplants include manipulation of difference in air temperature between photoperiod and dark periods (Kozai et al., 1992a), relative humidity (Tanaka, et al., 1992), PPFD (Kozai et al, 1992a), lighting direction (sideward vs. downward lighting) (Hayashi et al., 1992; Kozai et al., 1992b) (see Fig. 3), light quality (red/far-red) and mechanical stress (Kozai et al., 1992c). Figure 1 shows the effect of DIF and PPFD on the shoot length of potato plantlets cultured in vitro. The shoot length of potato plantlets in vitro increased with increasing DIF and decreasing PPFD.

Figure 2 shows potato plantlets cultured in vitro for 28 days in the sideward and downward lighting system. With the sideward lighting system, potato plantlets had shorter shoots, greater leaf area, and a lower shoot : root weight ratio compared to plantlets cultured in vitro with downward lighting system. A schematic diagram of sideward and downward lighting systems using fluorescent lamps is illustrated in Fig. 3. With this system, space for lighting can be reduced greatly. Asideward lighting system using diffusive optical fibers has been developed to reduce further the space for lighting (Kozai et al., 1992b). 


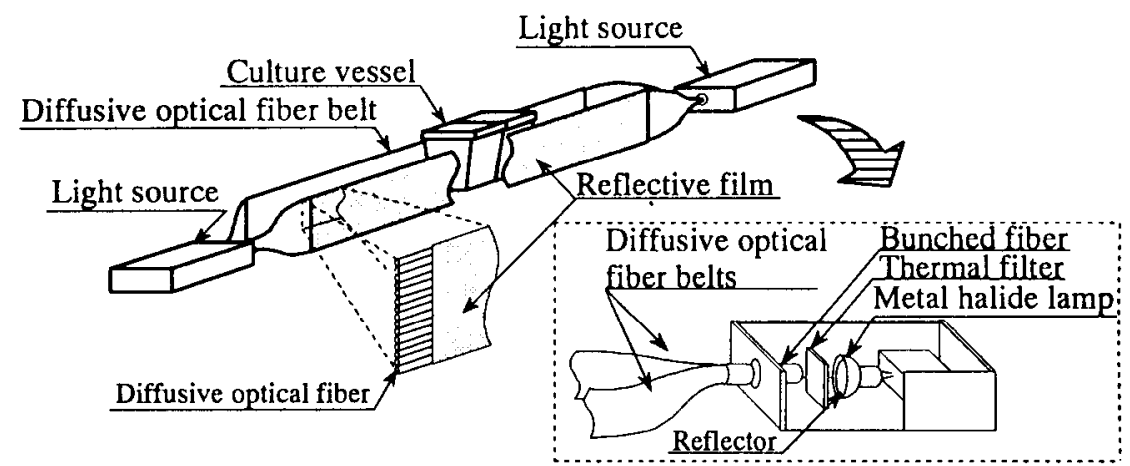

Fig. 4. A schematic diagram of the sideward lighting system using diffusive optical fibers (Kozai et al., 1992b).

Research on environmental control for producing vigorous and well-acclimatized transplants, such as CO, enrichment under high PPFD, has been conducted extensively in Japan (Kozai et al., 1992c). They have shown that chlorophyllous explants/plantlets in vitro can be grown photoautotrophically on the culture medium without sugar, as long as the in vitro environment is properly controlled to promote photosynthesis (Kozai et al., 1992c).

Development of automatic grafting systems by private companies is underway (Kurata, 1992). A prototype of an automatic grafting machine produces 1000 grafted transplants/h. This machine is expected to be available commercially in 1994. Development of automatic micropropagation systems for herbaceous and bulbous plants is also underway. Research on image processing for grading somatic embryos, explants, and transplants are being studied extensively at both public and private institutions.

\section{Literature Cited}

Hayashi, M., N. Fujita, Y. Kitaya, and T. Kozai. 1992 Effect of sideward lighting on the growth of potato plantlets in vitro. Acta Hort. 319:163-166.

Ito, T. 1992 Present state of transplant production practices in Japanese horticultural industry, $p$. 65-82. In: K. Kurata and T. Kozai (eds.). Transplant production systems. Kluwer, Dordrecht, the Netherlands.
Kozai, T, M. Hayashi, Y. Hirosawa, T. Kodama, and I. Watanabe. 1987. Environmental control for acclimatizationof in vitro cultured plantlets.J.Agr. Meterol. 42:349-358.

Kozai, T., S. Kushihashi, C. Kubota, and K. Fukiwara. 1992a. Effect of the difference between photoperiod and dark period temperatures, and photosynthetic photon flux density on the shoot length and growth of potato plantlets in vitro. J. Jpn. Soc. Hort. Sci. 61:93-98.

Kozai, T., S. Kinor, and B.R. Jeong. 1992b. A sideward lighting system using diffusive optical fibers for production of vigorous micropropagation plantlets. Acta Hort. 319:237-242.

Kozai, T, K Fujiwara, M. Hayashi, and J. AitkenChristie. 1992C. The in vitro environment and its control in micropropagation, p. 247-282. In: K. Kurata and T. Kozai (eds.). Transplant production systems. Kluwer, Dordrecht, the Netherlands.

Kurata, K. 1992. Transplant production robots in Japan, p. 313-329. In: K. Kurata and T. Kozai (eds.). Transplant production systems. Kluwer, Dordrecht, the Netherlands.

Natl. Fed. Agro Coop. Assn. 1991. A manual for grafted transplant production, Tokyo. p. 1-33.

Tanaka, K.., K. Fujiwara, and T. Kozai, 1992. Effects of relative humidity in the culture vessel on the transpiration and net photosynthesis rate of potato plantlets in vitro. Acta Hort. 319:59-64. 